some made from Etruria marl, containing about 11 per cent iron oxide. The kiln temperature was $1150^{\circ} \mathrm{C}$. The content of iron oxide (mainly $\mathrm{Fe}_{2} \mathrm{O}_{3}$ ), to which such ferromagnetic properties may be attributed, varies considerably in the materials from which bricks are made. It is usually well below 2 per cent in the fire-clays giving white and cream bricks, about 7 per cent in the clays giving red bricks, and 10 per cent or more in those giving blue and black bricks. Among recent relevant investigations are those of Koenigsberger (Phys. Z., 33, 468; 1932) on hæmatite $\left(\mathrm{Fe}_{2} \mathrm{O}_{3}\right)$, magnetite $\left(\mathrm{Fe}_{3} \mathrm{O}_{4}\right)$ and other ferromagnetic compounds. He finds that hæmatite, when cooled down in the earth's vertical field $(0.4$ gauss) from above the Curie point (about $670^{\circ} \mathrm{C}$.), shows a residual magnetisation which approaches the saturation remanence, and may be a considerable fraction of the saturation magnetisation. It is, of course, not possible to generalise about bricks. Each set of bricks presents a special problem, and precise discussion of the magnetic properties would require a detailed knowledge of the chemical composition of the clays, and of the conditions of baking and cooling. It is, however, probably not widely realised that most bricks are magnets-though feeble ones; and Mr. Bocking's observations are of interest in indicating that the phenomenon of thermo-remanence may be demonstrated with such a common object as an ordinary brick.

\section{A Remarkable Cloud Form}

A PHotograph of a remarkable cloud, of which a reproduction is shown in Fig. 1, has been received from Prof. I. S. Astapowitsch, of the Astronomical Institute, Fontanka 34, Leningrad. It was observed some time in 1932 at Stalinabad (lat. $38^{\circ} 34^{\prime}$ N., long. $68^{\circ} 47^{\prime}$ E.) above the Hissar Valley, and is described as having a rotational movement. Rotation round a vertical axis is strongly suggested by the appearance in the photograph of the middle and upper parts of the cloud. Students of cloud.

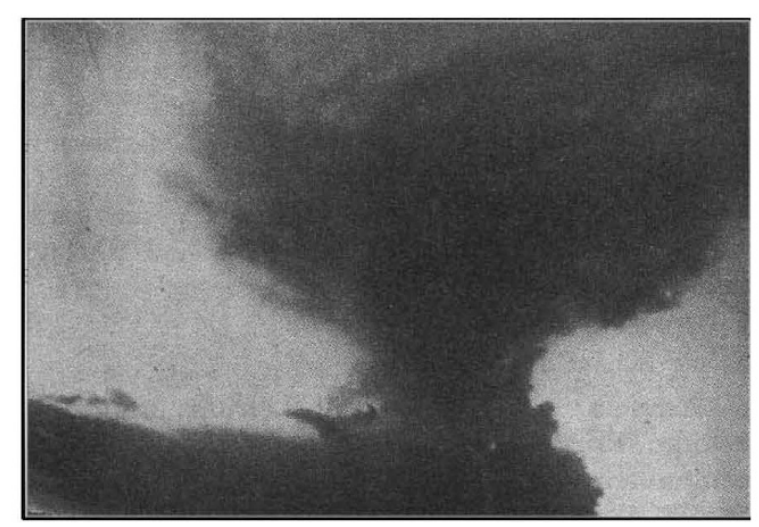

FIG. 1.

forms will recognise at once the very unusual character of this cloud, which has some structural resemblance both to the cumulo-nimbus cloud associated with a thunderstorm and to the funnel cloud of the tornado. By a curious coincidence, in a recent number of the Meteorological Magazine (Nov. 1934, vol. 69, No. 826) a sketch is shown of a cloud observed on October 4, 1934, near Waltham Cross, Hertfordshire, by Mr. Donald L. Champion, which has strong points of resemblance to the cloud just described. In each case a strong upward growth appears to have taken place over one part of a rather flattened cumulus cloud, the base of which was inclined to be convex, the central parts appearing to be lower than those farther from the centre. In the cloud near Waltham Cross the rapid vertical extension was formed in a few seconds, and after about five minutes the mushroom-shaped top spread out horizontally to form an 'anvil' cloud like those so often seen over thunder clouds. In both cases it is likely that opposed wind currents and convexion, perhaps associated with local heating, may have combined to produce rapid ascent of air with otation.

\section{Distribution of Birds at Sea}

Mos' ocean travellers must have noticed the very irregular distribution of birds on the open sea on different days, notwithstanding the apparently similar conditions of air and ocean. Censuses made during the crossing of the Atlantic record statistically these differences, but little attempt has been made to suggest a satisfactory reason for them. It seems very likely, however, that the presence or absence of pelagic birds is regulated by the oceanic currents, as S. C. Brooks suggests in the Condor (September 1934, p. 185). Oceanographers have shown that where the Arctic Current meets the North Atlantic Drift, there arise complexes of eddies and upwelling of the under waters, and that at the margin of contact there is a surface display of abundant organisms which attract fishes and other predators. This congregation of plenteous foodstuffs in limited areas may well attract pelagic birds, and Jesperson has already shown that there is a general connexion between the numbers of birds seen in a particular area at sea, and the quantity of macro-plankton in the surface waters. Pushing the probabilities further, it is likely that the migrations of oceanic birds may be related to the movements of plankton, by whatever determined, and tentatively Brooks makes the very interesting (but quite untested) suggestion that one of the factors which guided the homing terns of Bird Key from Cape Hatteras, to which they had been conveyed, back to the Tortugas, may have been the rich feeding grounds along the margin of the Gulf Stream. He adds that perhaps other factors too must be considered, such as the density of the air, which has been regarded as determining the northern limit of the distribution of the southern Atlantic wandering albatross.

\section{Flora of West Lancashire Dunes}

For some time, increasing concern has been felt amongst the botanists and Nature-lovers of this area for the dangerous position of the unique flora of the dunes of west Lancashire, particularly around Ainsdale. Recently two representatives of the Flora's League-a society for the preservation of wild flowers- 
Dr. C. T. Green, president of the Liverpool Botanical Society and author of "The Flora of Liverpool", and Mr. Eric Hardy, librarian of the Liverpool Naturalists' Field Club, made a special survey of the present status of the flora, with the consent of the Royal Society for the Protection of Birds, to find whether the latter's sea-bird sanctuary on the dunes is also serving as a wild flower sanctuary. The dunes are unique for their profusion of Pyrola rotundifolia (round-leaved wintergreen) and Parnassia palustris (grass of Parnassus), probably more numerous there than anywhere else in England, and these flowers have been banned from the wild flower collecting sections of the Southport flower show in order to protect the dunes. The duneland orchid (Epipactis dunensis), which so far has not been recorded from any other part of the country, was found growing abundantly on the dry dunes, beside the pinewoods, and in the thinner pinewoods, its only enemy being the rabbits. The area is rich in Orchidaceæ. According to the records of the Liverpool Flora Committee, Erythroea latifolia, the broadleaved centaury, which was first described from these sandhills by Shepherd and Bostock a century ago and has not been recorded from any other part of the country, is extinct, though profuse enough at the time of its discovery. The last specimen gathered from the sandhills at Formby is now in the collection at the British Museum (Natural History).

\section{Electrical Calculating Machine for Simultaneous Equations}

A MECHANICAL calculating machine for solving simultaneous linear equations up to ten in number under construction at the Massachusetts Institute of Technology by Drs. V. Bush and J. B. Wilbur was referred to in NaTURE of December 8 (p. 877). An electrical machine designed for the same purpose, also working up to ten equations, has already been designed by R. R. M. Mallock and constructed by the Cambridge Instrument Co., Ltd. A full account of this machine has been published (Proc. Roy. Soc., A, 140, 457; 1933) and a note on it appeared in Nature of June 17, 1933 (p. 880). The machine itself is set up and at work in the Engineering Laboratory, Cambridge. It is stated that this machine can determine rapidly a set of roots to an accuracy represented by about $0 \cdot 1$ per cent of the largest root in favourable cases when the equations are well conditioned. The fundamental principle of the machine is to use a number of alternating current transformers, the coils of which are coupled up to such numbers of turns as to represent a set of equations of condition for the fluxes through the transformers which are the linear simultaneous equations to be solved. Such machines promise to be of great value in the very large number of problems which can be reduced to the solution of such sets of equations.

\section{Physiographic Map of Japan}

AN instructive physiographic map or diagram of Japan on a scale of about 80 miles to an inch is published by Dr. G. T. Trewartha in the Geographical Review of July. Japan lends itself to this treatment since about seventy-five per cent of the land is mountainous and the lowlands are mainly peripheral. The diagram brings out in a striking way the contrasts between the main structural regions of Japan, that is to say, the inner and outer zones running the length of the islands and meeting in fault scarps and tectonic depressions, except in central Honshu where the great zone of depression cuts across the country and the rift is partly filled by later accumula. tions. The outer zone of Pacific fold mountains appears as a series of well-developed longitudinal ridges and valleys with few noteworthy plains, but separated in the south by subsidence into isolated mountain masses. By contrast the inner zone appears as a rugged hill country of dissected block plateaux, some upheaved and others depressed with much volcanic activity. The Inland Sea forms a notable area of depression in this zone.

\section{Tibet Earthquake of January 3}

As earthquake of moderate intensity occurred in southern Tibet early on January 3. According to the report issued from Kew Observatory, the first movements were recorded there at $2 \mathrm{~h}$. $0 \mathrm{~m}$. 58s., G.M.T., and at Bombay at 1 h. $54 \mathrm{~m}$. 23s. The epicentre was estimated to be 4,600 miles from Kew and 1,150 miles from Bombay, or in about lat. $30^{\circ} \mathrm{N}$., long. $88^{\circ} \mathrm{E}$., the time at the origin being $1 \mathrm{~h} .50 \mathrm{~m}$., G.M.T. The earthquake, though not of unusual intensity, is interesting as its epicentre lay about 120 miles to the south of that of the great earthquake of last December 15 (Nature, 134, 963, Dec. $22,1934)$.

\section{Third International Congress of Soil Science}

The Third International Congress of Soil Science will be held in Oxford, on July 30-August 7 this year, under the presidency of Sir John Russell. The two previous congresses of the series were held in Washington in 1927 and in Leningrad and Moscow in 1930, and were notable for the exceptionally international character of the personnel and the discussions. The Congress will meet as a whole in six plenary sessions, at which a general survey of recent advances in every branch of soil science will be made, and it will also work in sections or 'commissions' dealing specifically with (1) soil physics, (2) chemistry, (3) biology, (4) fertility, (5) classification, and (6) technology. Three sub-commissions will discuss problems relating to alkali, forest and peat soils respectively. A 16-day excursion round Great Britain leaving Oxford immediately after the Congress, and terminating in Cambridge on August 23, is being arranged for the benefit of members wishing to obtain first-hand knowledge of British agriculture and soils. Every member of the Congress will receive a copy of the official transactions, including the full text of papers read at the plenary sessions, and detailed reports of the discussions at the Commission sessions. The cost of the transactions will be included in the Congress fee (£2), payment of which will also entitle members to attend all meetings, receptions, etc., held in connexion with the Congress. College accommodation during the Congress can be 